\title{
Using Wikis for Online Group Projects: Student and Tutor Perspectives
}
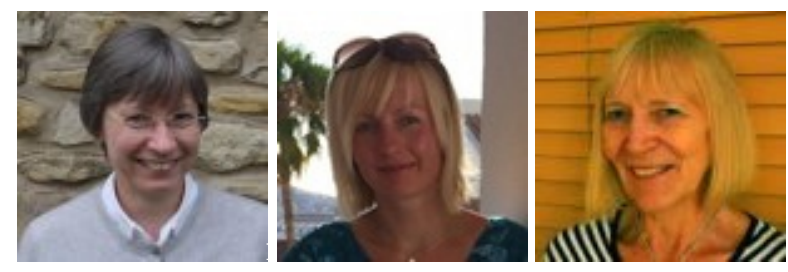

Karen Kear, Helen Donelan, and Judith Williams

The Open University, United Kingdom

\section{Abstract}

This paper presents a study of the use of wikis to support online group projects in two courses at the UK Open University. The research aimed to investigate the effectiveness of a wiki in supporting (i) student collaboration and (ii) tutors' marking of the students' collaborative work. The paper uses the main factors previously identified by the technology acceptance model (TAM) as a starting point to examine and discuss the experiences of these two very different user groups: students and tutors. Data was gathered from students via a survey and from tutors via a range of methods. The findings suggest that, when used in tandem with an online forum, the wiki was a valuable tool for groups of students developing a shared resource. As previous studies using the TAM have shown, usefulness and ease of use were both important to students' acceptance of the wiki. However, the use of a wiki in this context was less well-received by tutors, because it led to an increase in their workload in assessing the quality of students' collaborative processes. It was possible to reduce the tutor workload by introducing a greater degree of structure in the students' tasks. We conclude that when introducing collaborative technologies to support assessed group projects, the perceptions and needs of both students and tutors should be carefully considered.

Keywords: Wikis; collaboration; online learning; group projects; technology acceptance model 


\section{Introduction}

Group projects can help students to learn collaboratively about course topics and present their knowledge creatively. Group work can also be valuable for developing students' employability skills such as planning and interpersonal communication. However, successfully integrating group work into courses has its challenges, particularly in a distance learning or e-learning context. This paper discusses the implementation of a group project in a distance learning setting, and the role of communication technologies in supporting this implementation. The paper presents research findings on an initiative, which took place over several years, where wikis were used for online group projects in a course on information and communication technologies at the UK Open University. The aims of this initiative were to enable genuine student collaboration online and also to support tutors in the fair and efficient marking of the group projects.

The paper considers the students' and tutors' acceptance (or otherwise) of wikis, using the main factors identified by the technology acceptance model (TAM) as a theoretical basis (Davis, 1989). The TAM relates users' acceptance of new technologies to two primary factors: the usefulness and usability of the technologies. As the paper demonstrates, a user's judgement of these aspects depends on the tasks they need to carry out. In the initiative reported here, two sets of users were required to carry out different tasks: the students' main task was to collaborate in creating an extended piece of writing; the tutors' main task was to grade and give feedback on students' group work.

The research questions addressed in this paper are:

1. How effective is a wiki in supporting students who are carrying out an online group project?

2. How effective is a wiki in supporting tutors who are marking online group projects?

3. What roles do usefulness and usability play in students' and tutors' acceptance of wikis for a group project?

\section{Literature Review}

Group work has been the focus of much research, as there are many challenges involved (J aques \& Salmon, 2007). For example, groups need to agree on who will carry out which tasks and take on which responsibilities; they also need to negotiate schedules (Kear, 2011, p. 158). A particular issue is that success for an individual can rely on the group's performance, and this may cause tensions (Davies, 2009). In a distance or online learning context, where learners are expected to work with others whom they 
may never have met face-to-face, there are additional challenges (Hurst \& Thomas, 2008). The communication between group members needs to be facilitated through online communication tools, synchronous (real-time) or asynchronous. In addition, the output of the group's collaboration has to be created using shared online tools.

There has been considerable research into the use of various tools for supporting students in online group work (Dron, 2007; Mason \& Rennie, 2008; Olson \& Olson, 2008; Wang, 2010). For supporting communication between group members, online forums are often used successfully, although these also have disadvantages (McConnell, 2006; Kear, 2011). Synchronous technologies are effective for decision-making, but require group members to be available at the same time (Finkelstein, 2006; de Freitas \& Neumann, 2009). For creating a shared product, wikis and other shared websites have been investigated (West \&West, 2009).

Wikis provide a workspace to generate and communicate ideas and to construct, edit, and preserve shared knowledge in a readily accessible and open environment (De Wever et al., 2011; Wheeler et al., 2008). Research on assessment of students' web 2.0 activities has revealed that wikis are commonly used tools (Gray et al., 2012) and their effectiveness as tools for online collaborative learning has been identified (Ben-Zvi, 2007; Deters et al., 2010). However, studies show that the use of a wiki does not in itself result in true collaboration (Naismith et al., 2011; Witney \& Smallbone, 2011) and, in the context of wikis, a distinction needs to be made between collaborative working and cooperative working (Panitz, n.d.). Students' engagement with collaborative tasks using a wiki is dependent on a number of factors, including the availability of other online communication tools that students are more familiar with, the nature of the task, the context within which it takes place, and students' confidence in their own abilities (Benson et al., 2012; Whitney \& Smallbone, 2011; Cole, 2009). Further, it has been found that there is a reluctance for students to edit each other's work (Ben-Zvi, 2007; Kear et al., 2010), which impacts on the effectiveness of a wiki for collaborative authoring. When selecting collaborative tools, we need to consider these influences.

Once tools have been identified for a particular scenario, it is of value to consider users' acceptance, or otherwise, of the new tools. A research framework that has been used for this purpose by other researchers is the technology acceptance model (TAM). This is a well-known model for understanding why people accept or resist new technologies (Davis, 1989); it has been described as "arguably, one of the most widely adopted and tested across organisational contexts, technologies, and cultures" (Teo, 2009). The original TAM identified two key factors - perceived usefulness and perceived ease of use - as primary predictors of the acceptance of a technology. Perceived usefulness is a measure of whether an individual believes that a particular technology would enhance his or her job performance. Perceived ease of use is a measure of whether an individual believes that using a particular technology would be free of effort.

The TAM has been applied to many different contexts and technologies. Of particular relevance to the research presented here are applications of the TAM to e-learning 
(Roca \& Gagne, 2008; Edmunds et al., 2012), weblogs (Maditinos et al., 2012) and wikis (Liu, 2010). The TAM has been revised, supplemented, and combined with other models by various authors in different contexts (Venkatesh \& Davis, 2000; Brown et al., 2010; Abu-Al-Aish \& Love, 2013). In particular, intrinsic motivational factors have been the focus of research which has introduced elements such as perceived enjoyment (Lee et al., 2005; Venkatesh, 2000; Davis et al., 1992) and perceived playfulness (Roca \& Gagne, 2008; Moon \& Kim, 2001) to the model. The recent studies by Brown et al. (2010) and Madatinos et al. (2012) are of particular relevance as they examine the acceptance of collaboration technologies, and discuss the importance of social influence in group adoption of technology.

\section{Context of the Research}

The Open University is the largest provider of distance education in the UK, with over 250,000 students. It has a policy of open entry, enabling learners to access higher education whatever their background. Learners therefore have a wide range of prior educational and work experience, and the majority are in employment. Learners typically study part-time from their own home or workplace, over a period of nine months. Students are divided into tutor groups of around 20, with a tutor who is usually geographically local to them. The tutor provides support via group tutorials (held faceto-face or online), telephone, email, and online forums. The tutor also marks students' assignments (which are submitted electronically) and provides detailed feedback.

The initiative to use wikis began in the second level, 60-point course (equivalent to half of year 2 in an undergraduate degree) Information and Communication Technologies: people and interactions. The majority of students on this course were studying towards an undergraduate degree in Computing and IT. They were typically in the 30-49 age bracket and around three quarters were male. One of the intended learning outcomes for the course was the development of students' skills in group working via communication technologies. The course therefore included a period of study where students worked on an assessed group project. The design of the project was based on experience of group work in earlier modules (Kear, 2004). Students were assigned to project groups of up to eight members within their tutor group, with each project group given the task of producing a web resource about the concept of the cyborg. Students were provided with articles about different topics related to the cyborg concept. Each student created a web page about one of these topics, with the choice of topics discussed and allocated to individuals by the group. The group as a whole created an overview page to introduce the topics and link to the individual topic pages.

In the original project design, a set of HTML file templates was provided for each group to create their web resource, and students carried out the collaboration via an online discussion forum. The project included a peer review activity where each student submitted a draft of their web page to the forum as an attachment, and received 
feedback from two other group members; the logistics of this were a group responsibility to organise. In order to allocate marks and provide feedback, the tutor monitored the forum contributions as well as reviewing the web resource produced by the group. The groups were assessed on the web resource they produced (the product) and the collaboration that took place (the process) through an examination of the final webpages and contributions in the forum. Marks were allocated on both an individual basis and a group basis. The purpose of the group marks was to encourage shared responsibility. The purpose of the individual marks was to reward students for their individual efforts.

\section{Use of Wikis for the Group Project}

The research focused on the penultimate presentation of the course. At that time a wiki became an available tool within the Open University's new virtual learning environment (VLE). The course team decided to implement the use of a wiki for supporting the group project as a wiki seemed well-suited to the task set for students. Using a wiki in place of the HTML templates meant groups had a centralized resource to work with and it avoided the need for students to exchange updated versions of the material they produced. The wiki also provided a vehicle for the peer review activity which was an essential component of the task. In addition, the in-built history functionality of the wiki would provide an audit trail from which tutors could establish who had authored or edited the material.

Course tutors were given the option of offering wikis to their project groups; these student groups could then choose whether to use the wiki or to use the HTML templates. The wiki offered a simple discussion facility whereby participants could add comments to each other's pages, so groups could use the wiki for the peer review activity, as well as for developing their web resource. Nevertheless, a discussion forum was provided for each group, and group members could decide among themselves how to use and combine the wiki and the forum. The decision about how to use the wiki and forum were part of the challenge facing groups undertaking the group project. Deciding how to use multiple tools is an important part of any group work undertaken online.

The wikis were made available with several template pages already created. This ensured that groups using the wiki were provided with the same basic structure for creating their content as groups using the HTML templates. Unlike the HTML templates, the wiki templates included a 'Collaboration' page where students were required to document the process of their collaboration. As before, the groups were assessed both on the final product and on the collaboration that took place. Tutors marked the product by examining pages in the wiki, and marked the collaboration by looking at each individual's contributions to forum discussions (as before), together with evidence obtained from the wiki. 


\section{Research Methods}

\section{Student Data}

Of the 33 course tutors, 12 volunteered to take part in the research, and to offer the wiki to their student groups. Permission was requested from the Open University's Student Research Project Panel, which has university-wide responsibility for reviewing and approving research involving Open University students, to gather data from these students, via an anonymous online survey. The survey, which was created using the web-based SurveyMonkey facility, was designed to gain feedback from students on their use and perceptions of the wiki for the group project. Once the group project was submitted and marked, students in the 12 volunteer tutor groups (167 students) were invited to respond to the survey.

There were 10 survey questions, as shown in Table 1. Each consisted of a closed question with four or five options. The closed questions were intended to reveal whether and how students used the wiki, how useful they found it, and how easy it was to use. In this paper we later refer to the results of the closed questions (expressed as percentages) as the quantitative data. Each question also included an open-text area, where more descriptive comments were requested. We refer to this later as the qualitative data. The open comments provided by students enabled the issues to be explored in greater depth, identifying themes related to students' choices and perceptions. This provided an opportunity to investigate the significance of perceived usefulness and perceived ease of use to students' acceptance (or otherwise) of the wiki. In a novel approach we used the primary factors identified by the TAM as a basis for coding and analysing qualitative data. 
Table 1

Survey Questions

Closed question

1 Did your group use the wiki for the collaborative work in Module 3?

2 Did your group use the wiki for the collaborative work in Module 4?

3 Which of the following statements most closely matches your own experience of learning to use the wiki? [It took very little time [...]; It took a reasonable time [...]; etc.]

4 Which of the following statements most closely matches your own experience of using the wiki? [The wiki was very easy to use; the wiki was fairly easy to use; etc.]

5 Did the wiki provide all the features you needed?

6 How useful did you find the wiki in supporting the group's collaborative work?

$7 \quad$ How did you feel about group members being able to modify each other's contributions to the wiki?

8 Did group members contribute equally to creating and improving material in the wiki?

9 How did your group use the wiki and the group forum for the collaborative work?

10 How did you feel about having two communication tools available for the collaborative work?

\section{Prompt for open text area}

What were the group's reasons for using / not using the wiki in Module 3?

What were the group's reasons for using / not using the wiki in Module 4?

Please comment on your experience of learning to use the wiki:

Please give your thoughts on why it was easy or difficult to use the wiki:

Please comment on the features provided, and any features missing from the wiki:

Please give your views on the value of the wiki for the group's collaborative work:

Please explain your views about group members being able to modify each other's contributions:

Please give your comments on whether and how the work within the wiki was shared fairly:

Please describe how your group used the wiki and/ or forum:

Please give your views on the pros and cons of having both tools available:

Note. Modules 3 and 4 were the parts of the course where students were required to carry out collaborative work.

The prompts for the open text areas associated with Questions 1 and 2 asked students why their groups used, or did not use, the wiki. The comments received from students for these questions were coded independently by three researchers (the authors of this paper). The coding scheme, based on the factors identified by the TAM, comprised three primary elements. These were used in an initial round of coding: 
- PU, for comments relating to the perceived usefulness of the wiki;

- PEOU, for comments relating to the perceived ease of use of the wiki;

- O, for other comments.

The 'Other' category included comments that did not relate to either of the previous two elements: PU or PEOU. This meant that, whilst the two categories from the TAM could be explored in detail, the investigation was not restricted to these categories, and other emerging factors could be considered. This 'Other' category, and what emerged from it, is discussed later in the paper.

Following the independent coding, the percentage match between the three coders was calculated. Then the independently assigned codes were discussed by the research team in order to arrive at a final agreed code for each comment. The percentage matches and final results are discussed in detail in the Findings section.

\section{Tutor Data}

Feedback on the use of wikis was also sought from the tutors who took part, in order to gain their views and experiences of the wiki. Via a discussion forum, tutors were asked to comment on the following:

- whether they felt that wikis were beneficial to their students and/ or to themselves as teachers;

- $\quad$ any problems, for students or for themselves;

- $\quad$ whether wikis should be combined with other tools (e.g., forums or a real-time chat tool);

- $\quad$ any recommendations for how wikis could best be used in the future to support group work.

All the responses posted by the tutors were copied into a word processor document for coding purposes. The coding scheme was the same as that used for coding the qualitative student data: The data were coded independently by the three researchers, and then the independently assigned codes were discussed in order to arrive at a final agreed code for each comment. However, two issues emerged early in this process which resulted in some new considerations, as discussed below.

Firstly, the tutor data was in a less structured format than the student data. This meant that the units to be coded from the tutor data were not as easily identifiable, that is, some responses comprised one or two sentences whilst others were large paragraphs which could either be treated as one or multiple units to code. The decision was made to 
allow each researcher to independently code the data in its original format, with the intention to discuss the units of data at the discussion stage that followed.

Secondly, it became clear that a second dimension to the coding scheme was needed to indicate whether tutors' comments were related to the students' task (to collaboratively create a web-resource) or to their own task (to provide fair and efficient marking of the web resource and the collaboration). Therefore additional codes were used to distinguish comments that referred to the students' task (S) from those that referred to the tutors' task ( $\mathrm{T}$ ). In some cases comments applied to both ( $\&$ \& T).

\section{Findings}

The main findings are summarised below. The data from students (quantitative and qualitative) are presented first, followed by the data from tutors (qualitative only).

\section{Findings from Students: Quantitative Data}

Of the 167 students who were invited to complete the survey, 74 did so, giving a response rate of $44 \%$. Of these 74 respondents, 62 (84\%) reported that their groups used the wiki in Modules 3 and 4 (Questions 1 and 2). Because not all respondents had used the wiki, the remaining questions in the survey were answered by fewer than 74 respondents (between 61 and 69, depending on the question). In the following paragraphs, percentages are given in terms of the number of students who answered that particular survey question.

Responses to Question 3 indicated that most students found the wiki quick to learn, with $84 \%$ reporting that it took less than half an hour to learn how to use it. When responding to Question 4, 93\% said that the wiki was very or fairly easy to use. However, in response to Question 5, 43\% reported that there were some problems with missing or inadequate functionality. In response to Question 6, a large majority (82\%) reported that they found the wiki useful for the collaborative work.

In Question 7, most students (78\%) indicated they were comfortable about group members being able to edit each other's contributions in the wiki. For Question 8, most (70\%) reported that group members contributed equally or fairly equally to creating and improving material in the wiki. Question 9 revealed that the most common approach was to use the wiki for contributing material and to use the forum for discussion. Responses to Question 10 showed that nearly all (97\%) found it useful to have both the wiki and the forum available, but groups combined these tools in different ways (see Table 2). 
Table 2

How Groups Use the Wiki and the Forum for the Collaborative Work

Used the wiki for most of the collaborative work.

$15 \%$

Used the forum for most of the collaborative work.

$18 \%$

Used the wiki for contributing material and the forum for discussion.

$54 \%$

Used both the wiki and forum, but not as described above.

$11 \%$

Other

$2 \%$

\section{Findings from Students: Qualitative Data}

In the open comments boxes for Questions 1 and 2 of the survey, students elaborated on their reasons for using or not using the wiki. In total 60 comments were received on this issue. As described earlier, these comments were coded independently by three researchers, using the coding scheme $\mathrm{PU}, \mathrm{PEOU}$, and $\mathrm{O}$ to represent comments relating to perceived usefulness, perceived ease of use, and other issues.

The independent coding resulted in an initial $65 \%$ match between all three researchers and an $88 \%$ match between a minimum of two coders. When the codes allocated by each researcher were discussed, it was found that, where code allocations differed, this was usually due to difficulty in deciding whether a comment was related to usefulness (PU) or ease of use (PEOU). In some instances the comment related to both aspects, in which case the final agreed code was a double code (PU/PEOU). In a small number of cases, different combinations of codes (PU/O or PEOU/O) were also necessary.

A further interesting finding from the initial coding exercise was the range of comments that emerged within the 'Other' category. Upon coding the data, student comments relating to the following aspects emerged within this category:

- intrinsic motivation, comments relating to wanting a challenge or the opportunity to learn new skills;

- $\quad$ social influences, comments relating to peer influence within the group, tutor influence or expectations, and group decision making.

The distribution of codes across the 60 comments is summarised in Table 3. As the table shows, there was a significant number of comments in each of the main categories (PU, PEOU, and O). Comments were largely positive, and all the negative comments were related to ease of use (PEOU), sometimes in combination with other codes. 
Table 3

Coding of Comments from Students

$\begin{array}{llll}\text { Code } & \begin{array}{l}\text { Total number } \\ \text { of comments }\end{array} & \begin{array}{l}\text { Number of } \\ \text { positive } \\ \text { comments }\end{array} & \begin{array}{l}\text { Number of } \\ \text { negative } \\ \text { comments }\end{array} \\ \text { PU } & 17 & 17 & 0 \\ \text { PEOU } & 13 & 10 & 3 \\ \text { O } & 16 & 16 & 0 \\ \text { PU / PEOU } & 11 & 9 & 1 \\ \text { PU / O } & 1 & 1 & 0 \\ \text { PEOU / O } & 2 & 1 & 1\end{array}$

Students' comments on the usefulness (PU) of the wiki were mostly focused on the fact that it provided a central place for progressing the group's work. For example, one student comment was: "Good central location to collaborate on a single document."

Positive comments on ease of use (PEOU) referred to the wiki as being straightforward and intuitive to use: "Simple easy web tool, no hassle, straight forward and self explanatory."

The small number of negative comments about ease of use (PEOU) were directed at the limited editing functionalities of the wiki at that time. In particular, students wished to insert images, change or edit fonts, or copy text or tables from other word-processed documents.

As summarised earlier, comments from the third category, other $(\mathrm{O})$, highlighted that students welcomed the opportunity to embrace new technology: "We used the wiki because as a group we believed we could learn new skills."

In addition, comments were received about the social influences that contributed to decisions about using the wiki: "We took the decision as a group to utilize the benefits of the wiki environment."

\section{Findings from Tutors}

Of the 33 tutors, 21 offered the use of wikis to their student groups; this was considerably more than the 12 tutors who originally volunteered to take part in the research. As described earlier, feedback was elicited via a discussion forum. Seven of the tutors contributed to this forum and each responded to all the questions posed. 
The independent coding process for the tutors' comments resulted in a very close match in terms of how the data were treated as units to be coded, with only a very few paragraphs being treated differently by the three coders. These were discussed and a unit of data agreed in each case. In total, 34 units of data, that is, separate comments, were agreed on.

The independent coding resulted in an initial 68\% match between all three researchers and a $91 \%$ match between a minimum of two researchers. These figures are very similar to those for the coding of the student data.

The numbers of comments made for each code are summarised in Table 4 . The same primary codes were used (PU for perceived usefulness, PEOU for perceived ease of use, O for other). However, there were no comments that needed to be coded as $\mathrm{O}$ (other). The table also shows the additional coding of comments from tutors according to whether the comments related to the students' (S) task (collaborating in the wiki) or the tutors' (T) task (marking the group work) or both (S \& T). The table identifies whether the comments demonstrated a positive or negative perspective on that aspect.

Table 4

Coding of Comments from Tutors

$\begin{array}{llll}\text { Code } & \begin{array}{l}\text { Total } \\ \text { number of } \\ \text { comments }\end{array} & \begin{array}{l}\text { Number of } \\ \text { positive } \\ \text { comments }\end{array} & \begin{array}{l}\text { Number of } \\ \text { negative } \\ \text { comments }\end{array} \\ \text { PU-S } & 12 & 6 & 6 \\ \text { PEOU-S } & 10 & 5 & 5 \\ \text { PU/ PEOU-S } & 1 & 0 & 1 \\ \text { PU-T } & 4 & 3 & 1 \\ \text { PU- S\&T } & 3 & 2 & 1 \\ \text { PEOU- S\&T } & 1 & 0 & 1\end{array}$

As Table 4 shows, tutors commented most frequently about the students' use of the wiki, rather than their own use. Generally these comments were divided equally between positive and negative perspectives.

Positive comments on usefulness for students (PU-S) suggested that the wiki had encouraged collaboration and that it enabled students to keep track of the work: "It also enable[d] everybody to see who has contributed what and when the contributions were made." 
Negative comments on usefulness for students (PU-S) seemed to indicate that students were not using the wiki to its full potential: "I think that the Wiki [h]as tended to be a more 'final' document location for work discussed in the forum."

Positive comments on ease of use for students (PEOU-S) reported that students generally found the wiki easy to use, even if they had no previous experience. One tutor said that his students, "took to it like ducks to water. It seemed natural and intuitive."

Negative comments on ease of use for students (PEOU-S and PEOU-S\&T) were all related to the limited editing functionality of the wiki.

Tutors made no direct comments on the ease of use of the wiki in relation to carrying out their own task, but they did make some comments on its usefulness for them (PUT). These comments were mainly positive, as the tutors felt that the wiki functionality enabled them to see individual contributions: "I could see who made changes and when they were made."

Negative comments about the usefulness of the wiki for the tutors' task (PU-T) were about the increased workload associated with marking the collaborative work. However, these comments were not considering the use of the wiki on its own - rather the use of the wiki alongside the forum: "For me, the benefit[s] (I think) are less so. Having to keep an eye on [the forum] as well as wiki involved more effort."

\section{The Implementation of Wikis in the Replacement Course}

The replacement course Communication and Information Technologies maintained the online group project as part of its assessment and used a similar structure, but changed the topic that students were asked to write about from 'Cyborgs' to 'Online communication and collaboration'. Students were required to write web pages on topics such as virtual worlds, Web 2.0, and social networking. In the new course all students were required to use the wiki, as it had been well received by students in the previous course.

Again, students were required to work together in small groups to produce a set of linked wiki pages, including a 'Collaboration' page documenting group decisions. To write the content for the project, groups had to create their own 'Overview' wiki page, and ensure that this linked out to the pages for individual topics, which they also had to create. The peer review element was maintained from the previous course, with each student required to provide feedback and to use the feedback they received to improve their own page. A discussion forum was available to each group for coordinating and discussing group tasks.

As described previously, this research identified concerns about tutor workload, so feedback was collected from tutors on the new course to monitor this. The course team 
held three debriefing sessions for tutors via a synchronous web conferencing environment, and invited them to discuss the group project. Over the three sessions, 26 tutors attended, with a fairly equal distribution across the three sessions (9:8:9). In addition, tutors were asked to complete an end of course survey about their general experiences with the course. One of the survey questions asked them to identify assessments that were particularly slow to mark. This drew several comments regarding the group project, which revealed that assessing the collaborative process was proving to be time-consuming and difficult.

In the feedback via the debriefing sessions and survey, several tutors described the problems they were experiencing: "It was almost impossible [...] to identify contributions across several sources, wikis, forums etc. I think it was overcomplicated" (from a debriefing session) and "...collecting data on who has done what is time consuming” (from a debriefing session).

The tutors also offered suggestions which would ease their workload: "We should get the students to say what they have contributed" (from a debriefing session) and "Making it much clearer what's expected to be provided by the student, and what we're expected to find for ourselves" (from the tutor survey).

To make tutors' marking tasks easier, in subsequent presentations of the course more structure was added to the initial wiki template that students used. An overview page was created for students, and pre-defined headings were added to the 'Collaboration' page, where they were required to document aspects of the group process: 'Milestones', 'Problems', and 'Aspects that went well'.

\section{Discussion}

The findings from this research, both quantitative and qualitative, suggested that a wiki, used together with a forum, was a valuable tool for students working on group projects to develop a shared resource. However, the wiki was found to be of less value for the tutors who were marking the group work. Using a coding approach that was based on the main factors identified by the TAM, the researchers were able to examine the qualitative data in more detail, in order to understand students' and tutors' perceptions of adopting a wiki.

In the data from students about why they used the wiki, there were many comments relating to perceived usefulness and perceived ease of use. This implies that both these factors were important in students' adoption of the wiki for their collaborative work. This finding is consistent with TAM research, which suggests that usefulness and ease of use are key factors in technology adoption (Davis, 1989; Venkatesh \& Davis, 2000).

What also emerged from the student data was that factors other than usefulness and ease of use were important for students' decisions about whether to use the wiki. Some 
of these factors related to the desire to develop new skills or wanting a new challenge. Others were social factors, for example peer influence within the group or tutor expectations. These findings are in line with recent research which extends the TAM to include aspects such as intrinsic motivation (Lee, Chung, \& Chen, 2005; Venkatesh, 2000) and social influence (Brown et al., 2010; Madatinos et al., 2012).

Moving on to the tutors' point of view, the qualitative data from the 'early adopters' (i.e., those who volunteered to use the wiki with their student groups in the research) showed a fairly even balance between positive and negative comments. These tutors seemed to take a more critical stance on the technology than their students, and they were somewhat more critical of the wiki in relation to the students' task than their own. The coding scheme used allowed the researchers to explore the tutors' perceptions in greater detail. The tutors' comments about the students' task were relatively evenly balanced between usefulness and ease of use, while their comments on their own task were primarily about usefulness. There were no tutor comments coded as 'other', which suggests that there was no particular focus from tutors on personal motivations to use the wiki, or on social influences affecting its adoption.

Subsequently, in the implementation of wikis in the replacement course, tutors (who were all obliged to work with the wiki) were rather negative about using the wiki for their own task of marking students' collaborative work. They saw the wiki (in addition to a forum) as significantly increasing their workload because there were now two online spaces to monitor. As Trentin (2009) and De Wever et al. (2011) have pointed out, assessing group processes from the records provided by a wiki can be very timeconsuming.

Using the main factors identified by the TAM to develop a coding scheme for qualitative data is a novel approach adopted in this research. It was valuable to use the primary coding dimensions of 'perceived usefulness', 'perceived ease of use' and 'other' as this revealed other influencing factors, such as enjoyment/challenge and the various social influences, that emerged from the data. As with other approaches to coding qualitative data, it was found useful to have the qualitative data structured into identifiable units (sentences or paragraphs) to enable independent coders to treat the data in a similar manner. The initial independent coding exercise, which resulted in high percentage matches, provided confidence in the coding process. The iterative process of independent coding, research team discussion, and then final code allocation was useful for prompting discussion around problematic areas.

We now return to the research questions which were addressed by this study.

1. How effective is a wiki in supporting students who are carrying out an online group project? 
Both the quantitative and qualitative data from this study suggest that a wiki is effective for supporting student collaboration. Students found the wiki to be both useful and usable.

2. How effective is a wiki in supporting tutors who are marking online group projects?

The study revealed that use of a wiki, together with a forum, was perceived moderately positively by the 'early adopter' tutors, but more negatively by tutors in the large-scale implementation, who had concerns about their workload in marking the students' collaboration.

3. What roles do usefulness and usability play in students' and tutors' acceptance of wikis for a group project?

In this study, students' comments implied that usefulness and ease of use were both key aspects and that intrinsic motivation and social influence were also important factors. The tutors' comments about their own task of marking the group project implied that usefulness was the most significant factor in their acceptance of the wiki.

\section{Conclusion}

The research reported in this paper was concerned with an online project where student groups co-produced a web resource using a wiki. The research explored the perceptions of students on using the wiki for the group project, and the reactions of tutors who were required to mark the group work. Students found the wiki useful for their collaboration, and reasonably easy to use. Tutors were less receptive to the wiki because of the additional workload it presented in assessing the collaborative process. Subsequently, in order to reduce the tutor workload, further structure was imposed on groups by defining the wiki pages to be used, and how they were to be used.

Online collaboration technologies can play a key role in supporting learning and group work, especially in distance and e-learning contexts, but users' acceptance of these technologies is influenced by several factors. As proposed by the technology acceptance model (TAM), two primary factors are perceived usefulness and perceived ease of use. This research study suggests that these two factors are key to students' decisions to adopt a wiki. The TAM has been extended in previous works to include aspects such as social influence and intrinsic motivation. Social factors, for example peer influence and tutor expectations, were also identified in the current study, as were factors related to the desire to develop new skills or take on a new challenge.

This research makes a contribution to the existing literature by considering the TAM with respect to two different user perspectives of the same technology. We investigated students' acceptance of a wiki for undertaking collaborative group work, and tutors' 
acceptance of a wiki for enabling fair and efficient marking of an online group project. A key implication of this study for practitioners is that, when introducing online technologies to support collaborative activities and group projects, the perceptions and needs of both students and tutors should be carefully considered.

\section{Acknowledgements}

We would like to thank all the students and tutors who participated in this research. 


\section{References}

Abu-Al-Aish, A. \& Love, S. (2013). Factors influencing students' acceptance of mlearning: An investigation in higher education. International Review of Research in Open and Distance Learning, 14(5) 82-107. Retrieved from http:// www.irrodl.org/ index.php/irrodl/article/ view/ 1631

Ben-Zvi, D. (2007). Using wiki to promote collaborative learning in statistics education. Technology Innovations in Statistics Education, 1(1) Article 4. Retrieved from http:// escholarship.org/ uc/item/6jv107c7

Brown, S. A., Dennis, A. R., \&Venkatesh, V. (2010). Predicting collaboration technology use: Integrating technology adoption and collaboration research. J ournal of Management Information Systems, 27(2), 9-53.

Benson, R., Brack, C., \& Samarwickrema, G. (2012). Teaching with wikis: Improving staff development through action research. Research in Learning Technology, 20(2). Retrieved from

http:// www.researchinlearningtechnology.net/index.php/rlt/article/ view/ 1614 $\underline{9}$

Cole, M. (2009). Using wiki technology to support student engagement: Lessons from the trenches. Computers \& Education, 52(1), 141-146.

Davies, W. M. (2009). Groupwork as a form of assessment: Common problems and recommended solutions. Higher Education, 58, 563- 584.

Davis, F. D. (1989). Perceived usefulness, perceived ease of use, and user acceptance of information technology. MIS Quarterly, 13, 319-339.

Davis, F. D., Bagozzi, R. P., \&Warshaw, P. R. (1992). Extrinsic and intrinsic motivation to use computers in the workplace. J ournal of Applied Social Psychology, 22, 1111-1132.

Deters, F., Cuthrell, K., \& Stapleton, J . (2010). Why wikis? Student perceptions of using wikis in online coursework. MERLOT J ournal of Online Learning and Teaching, 6(1), 122-133.

De Wever, B., Van Keer, H., Schellens, T., \& Valcke, M. (2011). Assessing collaboration in a wiki: The reliability of university students' peer assessment. Internet and Higher Education, 14(4), 201-206.

Dron, J . (2007). Control and constraint in e-learning: Choosing when to choose. London and Hershey, PA: Idea Group Publishing. 
Edmunds, R., Thorpe, M., \& Conole, G. (2012). Student attitudes towards and use of ICT in course study, work and social activity: A technology acceptance model approach. British J ournal of Educational Technology, 43(1), 71- 84.

Finkelstein, J . (2006). Learning in real time. San Francisco: J ossey Bass.

de Freitas, S., \& Neumann, T. (2009). Pedagogic strategies supporting the use of synchronous audio conferencing: A review of the literature. British J ournal of Educational Technology, 40(6), 980-998.

Gray, K., Waycott, J ., Clerehan, R., Hamilton, M., Richardson, J ., Sheard, J ., \& Thompson, C. (2012). 'Worth it? Findings from a study of how academics assess students' Web 2.0 activities'. Research in Learning Technology, 20(1). Retrieved from http:// www.researchinlearningtechnology.net/index.php/rlt/article/ view/ 1615 $\underline{3}$

Hurst, D., \& Thomas, J . (2008). Developing team skills and accomplishing team projects online. In T. Anderson (Ed.), The theory and practice of online learning (2nd ed., pp. 441-472). Athabasca, Canada: AU Press.

J aques, D., \& Salmon, G. (2007). Learning in groups: A handbook for face-to-face and online environments. Abingdon: Routledge.

Kear, K. (2004). Peer learning using asynchronous discussion systems in distance education. Open Learning, 19(2), 151-164.

Kear, K., Woodthorpe, J ., Robertson, S., \& Hutchison, M. (2010). From forums to wikis: Perspectives on tools for collaboration'. The Internet and Higher Education, 13(4), 218-225.

Kear, K. (2011). Online and social networking communities: A best practice guide for educators. New York: Routledge.

Liu, X. (2010). Empirical testing of a theoretical extension of the technology acceptance model: An exploratory study of educational wikis. Communication Education, 59(1), 52-69.

Lee, M. K. O., Cheung, C. M. K., \&Chen, Z. (2005). Acceptance of internet based learning medium: the role of extrinsic and intrinsic motivation. Information \& Management, 42(8), 1095- 1104.

Maditinos, D. I., Therious, G. N., \& Keisidou E. (2012). Exploring the factors associated with weblog usage acceptance: Evidence from Cyprus. International J ournal of Web Based Communities, 8(2), 196-212. 
Mason, R., \& Rennie, F. (2008). E-learning and social networking handbook: Resources for higher education. New York: Routledge.

McConnell, D. (2006). E-learning groups and communities. Maidenhead: Open University Press.

Moon, J ., \& Kim Y. (2001) Extending the TAM for a world-wide-web context. Information \& Management, 38, 217-230.

Naismith, L., Lee, B.H. \& Pilkington, R.M. (2011) Collaborative learning with a wiki: Differences in perceived usefulness in two contexts of use. J ournal of Computer Assisted Learning, 27, 228-242.

Olson, G. M., \&Olson, J . S. (2008). 'Groupware and computer-supported cooperative work'. In A. Sears \& J .A. J acko (Eds.), The human computer interaction handbook: Fundamentals, evolving technologies and emerging applications (2nd ed., pp. 545-558). New York: Lawrence Erlbaum Associates.

Panitz, T. (n.d.). Collaborative versus cooperative learning: A comparison of the two concepts which will help us understand the underlying nature of interactive learning. Retrieved from http:// pirun.ku.ac.th/ btun/pdf/coop_collab.pdf.

Roca, J . C., \& Gagne, N. (2008). Understanding e-learning continuance intention in the workplace: A self-determination theory perspective. Computers in Human Behaviour, 24(4), 1585- 1604.

Teo, T. (2009). Is there an attitude problem? Reconsidering the role of attitude in the TAM. British J ournal of Educational Technology, 40(6), 1139 - 1141.

Trentin, G. (2009). Using a wiki to evaluate individual contribution to a collaborative learning project. J ournal of Computer Assisted Learning, 25, 43-55.

Wang, Q. (2010). Using online shared workspaces to support group collaborative learning. Computers \& Education, 55, 1270- 1276.

West, J . A., \&West, M. L. (2009). Using wikis for online collaboration: The power of the read-write web. San Francisco: J ossey-Bass.

Wheeler, S., Yeomans, P., \&Wheeler, D. (2008). The good, the bad and the wiki: Evaluating student-generated content for collaborative learning. British J ournal of Educational Technology, 39, 987-995.

Witney, D., \& Smallbone, T. (2011). Wiki work: Can using wikis enhance student collaboration for group assignment tasks?. Innovations in Education and Teaching International, 48(1), 101-110. 
Venkatesh, V. (2000). Determinants of perceived ease of use: Integrating control, intrinsic motivation, and emotion into the technology acceptance model. Information Systems Research, 11, 342-365.

Venkatesh, V., \& Davis, F. D. (2000). A theoretical extension of the technology acceptance model: Four longitudinal field studies. Management Science, 46(2), 186- 204.

\section{Athabasca University $\mathbf{Z}$}

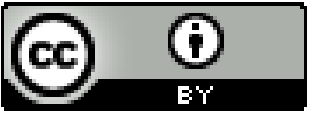

